\title{
Are consumers' quality perceptions influenced by brand familiarity, brand exposure and brand knowledge? Results from a wine tasting experiment
}

\author{
D. Priilaid*, G. Human, K. Pitcher, T. Smith and C. Varkel \\ School of Management Studies, University of Cape Town, Private Bag, Rondebosch, 7700, Republic of South Africa.
}

*To whom all correspondence should be addressed

david.priilaid@uct.ac.za

\begin{abstract}
Theory posits that, over time, placebo-type brand-equity effects may develop through the process of wine purchase and consumption. This being so, the extent to which factors like brand familiarity, brand exposure and brand knowledge combine to inform and reinforce such brand-equity effects remains still largely unexplored. With the aim of modelling this potentially mediating dynamic, we present a two-stage wine tasting experiment employing the combined reportage of fourteen experimental groups, each consecutively tasting seven Sauvignon Blanc wines first blind, and then, afterwards, sighted. Results demonstrate how brand familiarity mediates the effect of brand exposure on the sighted assessment of wine both directly, and via its relation to brand knowledge. This novel finding extends the literature on the consumer response to brand information, suggesting that conventional mass media marketing strategies aimed merely at imparting brand knowledge may prove insufficient unless they also create a degree of brand familiarity in the minds of their customers.
\end{abstract}

\section{Introduction}

The aetiology of brand affect is tied to a form of "system 1" conditioning (Kahneman, 2012). Classical-Pavlovian conditioning of this form is an important means by which hedonic preferences may develop and behaviour modification may occur, with a raft of empirical research demonstrating how conditioned consumers employ extrinsic marketing cues in the process of forming qualitative product judgements (Brucks, Zeithaml \& Naylor, 2000; Chocarro, Conrtiñas \& Elorz, 2008; Lockshin, Jarvis, d'Hauteville \& Perrouty, 2005; Plassmann, O'Doherty, Siegrist \& Cousin, 2009; Priilaid \& van Rensburg 2016). Thus, where two stimuli are co-joined, such as with a brand and its underlying intrinsic efficacy, over time and with repeated exposure, affect can be shifted from the one stimulus (the intrinsic quality) to the other (the brand itself) (Plassmann, Ramsøy, \& Milosavljevic 2012). In this study we further the analysis of brand-equity effects by examining the mediating influence of pre-existing states of brand familiarity, brand knowledge and brand exposure in the purchase and consumption of wine.

Forms of cue-based product assessment may derive from any number of extrinsic sources including: brand name, product price, expert ratings, prior knowledge and level of category involvement. With specific reference to the influence of brands, across a broad array of product categories including pain medication, beer, yoghurt, fast-food hamburgers, and sugar drinks, there is substantial evidence of subjects employing brands as heuristic enablers (Allison and Uhl, 1964; McClure, Li, Tomlin, Cypert, Montague \& Montague,
2004; Pasovaara, Luomala, Pohjanheimo, and Sandell, 2012; Robinson, Borzekowski, Matheson \& Kraemer, 2007; Shiv, Carmon, \& Ariely, 2005; and Waber, Shiv, Carmon, \& Ariely, 2008).

According to Aaker (1996), brand affect is fuelled by factors such as brand perception, associated levels of consumer awareness and loyalty, and perceptions of quality, and equates to a version of brand equity. Where situations exist that intrinsic merit cannot be readily attested, as in the purchase of wine, extrinsic brand cues have additionally been shown to serve as placebo-type proxies employed in determining brand equity (Thrane, 2004). In an assessment of wine brand-equity effects manifesting across a range of demographic transects, Priilaid, Barendse, Kato-Kalule \& Mubangizi (2013) conducted a wine-based tasting room experiment premised on a view that brand effects may be specified and measured as the difference between a sighted and blind product sampling. Where the sight-to-blind ratingdifference is found to be statistically consistent, this difference may serve as a legitimate proxy for brand equity (Kamakura \& Russell, 1991 and Keller, 1993).

In their study, Priilaid et al. (2013) asked their subjects to assess different entry-level rosé wine brands, first blind and then sighted. Analysing the sighted-to-blind differentials, two significant findings emerged: (1) how some brands present more dominantly than others, and (2) how such dominance may present differentially across different user profiles, with, for example, some brands more favoured by men than by women, and vice versa. 
While showcasing a cost-effective means for testing the presence of particular brand effects across user categories, the Priilaid et al. (2013) study was, however, subject to certain limitations. Most critically, it failed to consider the potentially mediating effects of any pre-existing degrees brand familiarity. According to Tam (2008), brand familiarity is a function of the number of indirect and direct product-related experiences with a particular brand, and is regarded as crucial to predicting consumer behaviour: with familiar brands thus possessing significant communication advantages since they can be recognized more easily than their lesser cousins (Delgado-Ballester, Navarro \& Sicilia, 2012). By extension therefore, familiar brands receive benefits in terms of increased consumption and greater perception of quality (Labroo \& Lee, 2006; Lee \& Labroo, 2004; Novemsky, Dhar, Schwarz \& Simonson, 2007). In the 2011 study of wine purchasing behaviour by Sherman \& Tuten, brand familiarity and price were found to be the most important factors determining consumer choice.

With this in mind, our study asks whether and / or to what extent certain dimensions of brand awareness might mediate the sighted assessment of wine, when controlling for blindbased intrinsic merit. Worth noting here is that blind tastings are void of subjective bias since they carry no extrinsic information. In blind tests, therefore, individual may rely only on the intrinsic properties inherent in the wine itself. In a sighted tasting however, the consumer is subject to the influence of both intrinsic merit and any extrinsic cues. Thus where the extrinsic cue is a brand, associative dimensions of brand familiarity, brand knowledge and brand exposure arguably come in to play. This being so, through the consequent control of blind measures of quality, the influence of a particular brand cue on any subsequent sighted assessment may thus be flagged and computed, in conjunction with the potentially mediating effects of one's declared familiarity, exposure and knowledge of the brand in question. Note that from here-out the brand familiarity, brand exposure and brand knowledge constructs are respectively foreshortened to $\mathrm{BF}, \mathrm{BK}$ and $\mathrm{BE}$.

Through the application of the BF, BK and BE constructs, this study reports on a two-stage tasting experiment in which 140 subjects assessed seven different sauvignon blanc wines first consecutively blind (round one) and then consecutively sighted (round two). Each of the 140 subject's seven paired blind and sighted wine assessments were subsequently aggregated with certain biographical details and selfdisclosures of $\mathrm{BF}, \mathrm{BE}$ and $\mathrm{BK}$, as applied to each brand in question. Thus a dataset incorporating 980 (7x140) wine assessments was constructed to determine the presence of any brand-effects at a generalised level of sample, as well as within certain specified demographic sub-groupings. Following this preliminary analysis, the data of any brandaffective sample-sets was then pooled and reinterrogated to determine the mediating role of $\mathrm{BF}, \mathrm{BE}$ and $\mathrm{BK}$ in the brandaffective process. It is this reinterrogation - essentially the second component of the experimental analysis - that serves as the primary focus of our paper.
Following this introduction, we review the relevant literature, providing a conceptual overview of consumption behaviour in the presence of brand-type extrinsic cues. This is followed in section three with a description of the experimental design and dataset. Thereafter in section four's presentation of results, we report on the parallel mediation model describing the mediating effect of $\mathrm{BF}, \mathrm{BE}$ and $\mathrm{BK}$; with section five concluding.

\section{Literature review}

This section (1) reviews the role of heuristic cues and their influence on general consumption and of wine in particular; and (2) examines the role of brands and brand equity to the extent that they inform questions of $\mathrm{BF}, \mathrm{BE}$ and $\mathrm{BK}$.

\section{Influence of heuristic cues on consumer perceptions}

There is considerable literature on the deployment of placebo-type marketing cues in the consumption process. An initial study conducted by Allison and Uhl (1964) sought to determine whether consumers could distinguish between major beer brands when unlabelled. Results revealed that during a blind (unlabelled) assessment, respondents ranked the beers as tasting similar and could not distinguish between the brands. However, on sighted inspection, respondents could both rank the beer brands and demonstrate that the brand they most frequently consumed was the one with superior quality. This and subsequent studies by Erdem \& Swait (1998), McClure et al. (2004) and Shiv et al. (2005) all conclude that expectations set by brand-related marketing efforts can influence and in some cases outweigh the intrinsic merit of the product at hand. The findings of the Allison and Uhl (1964) study also support the Ariely \& Norton (2009) notion of "conceptual consumption", which is the psychological consumption of ideas and concepts occurring either with or independent of physical consumption. Classic consumer behaviour theory has concluded that the physical consumption of products and brands not only satisfies a basic need but serves also as a confirmatory signal to ourselves and to others of our beliefs, attitudes and identities (Fournier, 1998; Hirschman \& Holbrook, 1982; Holbrook \& Hirschman, 1982). As such, conceptual consumption is connected to even the most basic forms of consumption (Ariely \& Norton, 2009).

In a further piece by McClure et al. (2004) respondents indicated their preferences for Pepsi and Coke both in blind and sighted tastings. In the absence of brand information respondent's preference for Pepsi and Coke were split equally. However, in sighted tastings respondents showed a clear preference for Coke. More interestingly, through the use of fMRI scans, McClure et al. (2004) showed that in the case of Coke especially, the respondents' preferences were reflected in the recruitment of brain regions typically associated with reward; these results confirming the primacy of brand association in the configuration of consumer preferences (McClure et al., 2004). 


\section{Cue-effects in wine}

Wine assessments are also prone to variations of cue persuasion, with the literature confirming the efficacy of price (Plassmann et al. 2008), expert opinion (Priilaid, Feinberg, Carter and Ross, 2009) terroir (Priilaid, 2007) and brand (Plassmann et al., 2008; Priilaid \& Van Rensburg, 2010; Siegrist \& Cousin, 2009). Win-based cues are of particular relevance since purchasers of wine have low levels of predetermination, characteristically only making their purchase decisions while in store (Seghieri, Casini \& Torrisi, 2007). In shelf-facing situations, extrinsic cues are typically employed as proxies of genuine utility, and it is here that brand effects become particularly discernible.

A recent study, Priilaid et al. (2013) investigated the extent to which brand cues present across particular demographic profiles including age, gender, wine expertise and education. Using a blind-to-sighted tasting metric, in conjunction with demographic information obtained by questionnaire, the study found significant variation in brand equity effects across bands of education and gender. Though thus novel in its method of identifying brand effects across particular userstrata, the Priilaid et al (2013) study did not address the potentially intervening issue of BF. Specifically, while this study observed merely the presence and relative strength of certain brand-equity effects, it did not consider whether and how BF, BE and / or BK might serve as mediators of these effects. On the basis of classical conditioning, it stands to reason that a subject more familiar with a certain brand would demonstrate more degrees of affectation than one who was not (Shiv et al., 2005). The following section lends special focus to this particular topic.

\section{Brands and brand equity}

Kotler \& Armstrong (2010) define a brand as a name, term, sign, symbol, design, or a combination of these, intended either to identify the goods and services of a seller, or to differentiate their product offering from those of their competitors. These various brand identities typically combine with memory principles such as BE, BK and / or BF to interpret product cues such brand and price in the construction of some form of relationship to the brand in question (Keller, 1993).

As defined by Kamakura and Russell (1991) brand equity is the differential effect of BK on consumers' response to the marketing of a brand; and is known to manifest when the consumer is familiar with the brand, and holds some favourable, strong and unique brand associations resulting in brand loyalty and ultimately the possibility of some form of brand extension (Keller, 1993). Erdem \& Swait (1998) define brand equity more simply as the perceived value ascribed to brands by consumers. Similarly, Aaker (1996) and Keller (1993) define brand equity in terms of those marketing effects uniquely attributable to the brand, which result in credible and sensitive measures of brand strength.
Keller (1993) also notes that the source of brand equity lies in consumer perceptions of the brand. These can be examined from both financial and customer-based perspectives. The customer-based response to a product or brand is the driving force for incremental gains to the firm and positively influences financial performance (Keller, 1993; Lassar, Mittal, \& Sharma, 1995). Lassar et al. (1995) maintains that brand equity may also refer to the global monetary value associated with the brand, and is best understood in relation to competitor brands (Lassar et al., 1995). On this basis, Lassar et al. (1995) specifies brand equity as the enhancement in the perceived utility and desirability a brand name confers on a product. It is the consumer perception of the overall superiority of a product carrying that brand name when compared to others.

In our study brand equity is thus defined as the perceived utility and desirability a brand name confers to a product. Clearly a key determinant of brand equity is the idea of BF which in itself is a function of the number of past positive brand-product experiences. For the consumer these experiences assist as cue-flags in the search for future offerings of value and reward. It is this value or reward ascribed specifically to the brand relative to other nonbranded products that comes to constitute brand equity.

\section{Brand exposure, brand knowledge and brand familiarity}

Though closely related the BE, BK and BF constructs present as alternate dimensions of brand association. For the purpose of this study, we specify BE as the degree to which a customer is witnessed to a particular brand across a range of touch points (as per Aaker, 1996), and BK as a function of informative marketing (as per Delgado-Ballester et al., 2012). As defined by Tam (2008) BF relates to the aggregate number of product-related experiences per consumer. Such experiences may be direct or indirect, and include advertising, product usage, interactions with employees and word-of-mouth communications (Tam, 2008). BF plays an important role in purchasing behaviour as it has been found to be one of the key differentiating features among brands (Delgado-Ballester et al., 2012). With evidence suggesting that familiar brands have distinctive communication advantages stemming from their requiring less mental storage, retrieval and processing effort, $\mathrm{BF}$ is thus deemed essential for commercial success (Delgado-Ballester et al., 2012; Lange \& Dahlén, 2003). Owing to the knowledgedifferential existing between familiar and unfamiliar brands, consumer attitudes towards familiar brands tend thus to be more favourable (Dahlén \& Lange, 2004; Delgado-Ballester et al., 2012). With familiar brands more easily recognised, they posses thus both cognitive and affective advantages (Labroo \& Lee, 2006; Lee \& Labroo, 2004; Novemsky et al., 2007).

Marketing efforts play a crucial role in increasing BK, as its function is to remind, inform and persuade consumers about the product in question (Delgado-Ballester et al., 2012). However, due to rising advertising costs and increases in the 
variety of available media options and growing competition, it is becoming increasingly difficult for marketers to build BK and BF. Consequently, it is therefore necessary for organisations to coordinate towards consistent brand messages (Delgado-Ballester et al., 2012). From a strategic perspective, consistency requires sharing common brand content through various communication touch points (Keller, 2003), a practice critical to the building of brand image and BF (Madhavaram, Badrinarayanan \& McDonald, 2005).

Wine selection can be a complex and risky decision because its intrinsic merit cannot be readily assessed at the time of the purchase. Thus a consumer's evaluation of the wine's quality can only be determined post purchase. In the purchaseselection of wine, consumers use a variety of extrinsic cues to assist them in selection. As discussed, the brand is one such cue, and here familiarity is crucial (Sherman \& Tuten, 2011). As consumers become repeatedly exposed to a particular brand of wine, they gain BF. In turn, this decreases risk in the selection of (Yuan \& Jang, 2008). A study conducted by Sherman \& Tuten (2011) evaluated the relative importance of strategic factors affecting wine purchasing decisions. These factors included country of origin, BF, year bottled, wine ranking, label appearance, region, brand name appeal and price. Their findings indicated that while the choice of wine is dependent on the occasion for which the wine is being consumed, the first factor driving a consumer's wine choice, irrespective of the occasion, is the type of wine, followed by $\mathrm{BF}$ and price. Notably, when wine is consumed in a social setting, and is likely to be judged by others, BF becomes more important than price (Sherman \& Tuten, 2011).

In the light of the above and following on from the deficiencies in the study by Priilaid et al's. (2013) brand equity formulations, we hypothesise that $\mathrm{BF}$ mediates the effect of BE on sighted taste assessments in two ways:

\section{$H_{1}$ : $B F$ mediates the relationship between $B E$ and the sighted taste assessments of wine.}

\section{$H_{2}$ : $B F$ mediates the relationship between $B K$ and the} sighted taste of wine.

Additionally, and in accordance with Kamakura and Russell (1991) and Delgado-Ballester et al., (2012), we further hypothesise that:

\section{$H_{3}$ : $B K$ mediates the effect of $B E$ in sighted taste assessment of wine.}

The configuration of these three hypotheses is illustrated in the model specified in Figure 1.

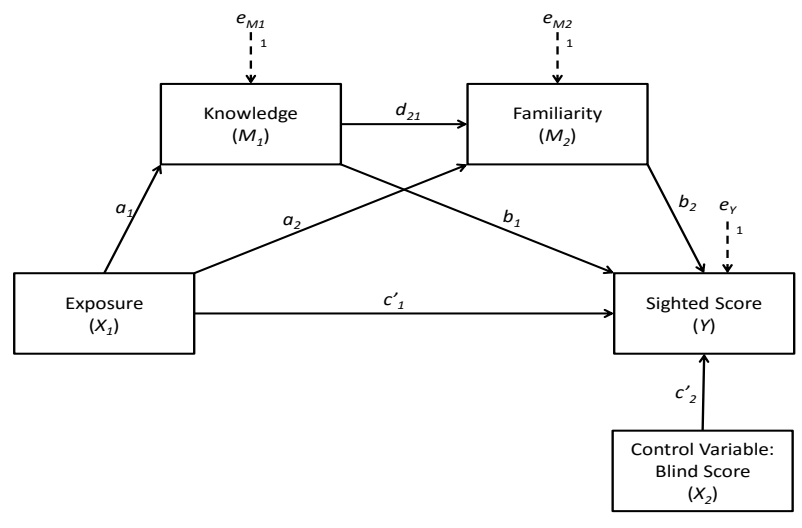

Figure 1: The BF, BK and BE model specification for mediation analysis.

\section{Methodology}

\section{Research method and sample design}

Since this study seeks (a) to consider the relationship between $\mathrm{BE}$ and the sighted influence of a brand (dependent variable) when controlling for blind-based merit, and the mediation effects of (b) BK and (c) BF; we followed the general approach for a conclusive research design as suggested by Malhotra (2010). So doing we adopted the same one group pre-experimental design-format employed by Priilaid et al. (2013) in their measure brand equity effects driving consumer perceptions of quality of Rosé wine. The target population in our study consisted of respondents over the South African legal drinking age of eighteen years old and living in Cape Town. Both male and female consumers were targeted.

Respondent quality assessments remained anonymous since anonymity has been found to increase the honesty and accuracy of quality assessment by respondents (Durant, Carey \& Schroder, 2002). The sample frame included South Africans over the age of 18 years as that is the legal age limit for the consumption of alcohol. In addition, a snowball quota sampling allowed us to find referrals of respondents who meet the criteria for the target population (>18 years) and ensure an even split between males (47\%) and females (53\%). As per Kerr, Greenfield, Tujague, \& Brown (2005), various consumption studies on beer, wine and spirits suggest that the under-sampling of younger drinkers and minorities is likely to occur because of legal and societal limitations. In this study therefore, the quota sampling also ensured a fair representation of drinkers across all age strata.

\section{Measurement instrument}

Other than the capture of basic demographic data (age, gender, wine expertise, frequency of wine consumption, preference for red or white wine, and typical spend per bottle of wine), the self-administered questionnaire contained two empirical components. The first was a single measure of utility experienced when sampling wines both blind and sighted. This measure was based on that of Priilaid et al. (2009) and employed an 11 point scale using 0.5 increments 
ranging from 0 to 5 using "half star" increments, with 0 being the 'Worst Possible' and 5 being the 'Best Possible'.

As specified in Bruner's (2013) Marketing Scales Handbook, the second component included three separate questions aimed to measure $\mathrm{BF}, \mathrm{BK}$ and $\mathrm{BE}$, respectively. Each of these measures employed a seven-point semantic differential scale, as previously employed by Zhou, Yang \& Hui (2010); with origins rooted in work by Steenkamp, Batra \& Alden (2003) and Oliver \& Bearden (1985). The questions relating to $\mathrm{BF}, \mathrm{BK}$ and $\mathrm{BE}$ run respectively as follows:

(1) The brand is very familiar to me (BF),

(2) I'm knowledgeable about this brand (BK), and

(3) I have seen advertisements about this brand in the mass media (BE).

\section{Experiment design}

For ease of implementation, the study-experiment was broken into fourteen smaller experimental groups, each consisting of ten respondents, creating thus a total sample size of 140 . Each respondent was taken through a two-stage blind-thensighted Sauvignon Blanc wine assessment, with a different pre-specified wine-line up employed in each blind and sighted round. The sequence of events ran as follows. (1). Prior to the commencement of the blind round, by way of a questionnaire, respondents were requested to provide information on biographic details including age, gender and level of expertise, as well as typical spend per bottle, wine consumption per week, and wine preference: red, white or indifferent. (2). Subjects then tasted each of the seven wines blind, one after the other, recording their assessment ratings as they went. At this stage subjects were aware only of the cultivar of the wines sampled (Sauvignon Blanc). No other extrinsic cues were disclosed. The blind tasting thus allowed the researchers to assess the respondent's perception of the quality of the wine without the influence of extrinsic cues. (3). Completed questionnaires from the blind tasting were then collected from the respondents to ensure that respondents did not change their initial ratings once they were exposed to the brand cue. Water and crackers were provided throughout to allow respondents to cleanse their palates between each wine. (4). Prior to the sighted round of tasting, subjects were requested to indicate their level of familiarity with each of the wine brands they were about to taste (See Table 1 below). (5). Thereafter followed the second "sighted" round in which the brand of each of the seven wines was the only additional cue information available.
Table I: List of Sauvignon Blanc's used in the experiment. These wines were directly sourced through sponsorship from the respective wine estates. Prices, as of 2013, are not disclosed to subjects and quoted here merely for interest.

\begin{tabular}{c|c|c}
\hline & Estate & Price $($ ZA) \\
\hline 1 & Groot Constantia & R80.00 \\
\hline 2 & Rustenberg & R76.00 \\
\hline 3 & Hartenberg & R75.00 \\
\hline 4 & Thelema & R70.00 \\
\hline 5 & Avontuur & R68.00 \\
\hline 6 & Fairview & R68.00 \\
\hline 7 & Durbanville Hills & R52.99 \\
\hline
\end{tabular}

\section{Data description}

Merging the data relating to the seven wines rated blind and sighted with information drawn from the 140 selfadministered questionnaires (74 female and 66 male), a dataset of 980 (140x7) paired wine assessments and demographic control variables was assembled. Descriptive statistics pertaining to the subjects of the dataset are provided in Table 2 below. In order to assess the normality of the data both kurtosis and skewness were assessed. Kurtosis values for all variables, except age, fell between -1.5 and 1.5 indicating normality. Similarly, assessment of skewness showed data, except that of age, to fall between -1 and 1 , thereby indicating normality. This was expected as diverse age strata, ranging from 18 to 82 years old, were used. Thus normality was assumed.

\section{Table 2: Descriptive statistics}

\begin{tabular}{c|c|c|c|c}
\hline & & & & \\
& & & & \\
& & & & \\
& & & & \\
\hline Minimum & 0 & 0 & 18 & 0 \\
\hline Maximum & 5 & 5 & 82 & 8 \\
\hline Median & 3 & 3 & 23 & 2 \\
\hline Mode & 3.5 & 3.5 & 22 & 0 \\
\hline Mean Average & 2.89 & 2.84 & 27.98 & 1.9 \\
\hline Standard & 1.02 & 1.08 & 13.99 & 1.86 \\
\hline Deviation & 5 & 5 & 64 & 8 \\
\hline Range & -0.41 & -0.20 & 4.28 & 0.50 \\
\hline Kurtosis & -0.43 & -0.54 & 2.30 & 0.96 \\
\hline Skewness & 980 & 980 & 140 & 140 \\
\hline N & & & & \\
\hline
\end{tabular}

\section{Model construction}

Conventional testing for mediation typically occurs through assessing whether the independent variable has a significant effect on the dependent variable after the inclusion of a mediator variable. In this way mediators might for example explain how external physical events take-on internal psychological significance (Baron \& Kenny, 1986). While in the past this approach has led to introducing mediating variables one at a time, recent advances in mediation analysis now allow for the simultaneous testing of multiple mediation 
effects. Thus, to consider the mediation effect of BF and BK on the relationship between $\mathrm{BE}$ and sighted assessments we followed the procedures for parallel mediation analysis proposed by Preacher \& Hayes (2008) and Hayes \& Preacher (2012). The earlier Figure 1 depicts these variables showing how the model considers (1) the indirect effect of $X$ on $Y$ via $M_{i}\left(\mathrm{a}_{i} b_{i}\right),(2)$ the indirect effect of $X$ on $Y$ via $M_{1}$ and $M_{2}$ $\left(\mathrm{a}_{1} \mathrm{~d}_{21} \mathrm{~b}_{2}\right)$ in serial, and (3) the direct effect of $X_{1}$ on $Y$ while $X_{2}$ is a covariate.

Given the model specification it is suggested that the respondent's familiarity with the brand drives his or her knowledge of the brand which in turn can mediate the relationship between the respondent's exposure to the brand and his or her sighted assessments of the brand. This mediation might occur either separately $\left(a_{1} b_{1}\right)$ or together $\left(a_{1} d_{21} b_{2}\right)$.

To test for mediation effects the data of each brand-affective sample was aggregated to produce scores for each measure of sighted assessment, blind assessment, BF, BK, and BE. This means that the individual item scores for each respondent were used to compute a mean score for each construct at the respondent level. This aggregated approach is consistent with the recommendations of Hayes \& Preacher (2012) when employing parallel process analysis. The individual mean scores per brand identified were then combined to reflect the means of the 446 (n) respondents who identified these effects. (To elaborate: as per the summary table in the appendix, these 446 respondents were drawn, and consequently aggregated, from the following brand-equity models: meta-model $(n=140)$, age 18-27 model $(n=113)$, male model $(n=66)$, female model $(n=74)$ and non-novice model: $n=53$; sum = 446. Each these five models presented with identifiable brand effects.) Note that the procedure suggested by Hayes \& Preacher (2012:649) is "general in that it can be used for any model linear in its parameters that is differentiable with respect to $X$ and $M$ in the range of the data available, and it encompasses the linear model as a special case." Importantly, the method is useful for assessing indirect effects in models containing nonlinear parameters. It is therefore common to see it applied when the functional relation of two variables cannot be expressed as the product of a slope and a function of a predictor variable.

\section{Results}

\section{Mediation model}

The following section evaluates the hypotheses applied respectively to the mediating roles of BF and BK. The output from the predictive model is shown to explain $57 \%$ of the variance in $\mathrm{BK}\left(\mathrm{R}^{2}=0.57\right), 73 \%$ for $\mathrm{BF}\left(\mathrm{R}^{2}=0.73\right)$, and $15 \%$ for sighted assessment $\left(\mathrm{R}^{2}=0.15\right)$. Moreover, the results (reported in Table 3 below) demonstrate the presence of statistically significant mediation effects. In particular the joint mediation effect of $\mathrm{BK}$ and $\mathrm{BF}$ on the relationship between $\mathrm{BE}$ and sighted assessment scores is statistically significant at the $95 \%$ level, and thus the null hypothesis is rejected in favour of $\mathrm{H}_{1}$. Similarly the mediation effect of $\mathrm{BF}$ on the same relationship is also statistically significant that the $95 \%$ level. Thus once more the null hypothesis is rejected in favour of $\mathrm{H}_{2}$. These results however do not support a mediation effect of BK on the relationship between BE and sighted scores and thus the $\mathrm{H}_{3}$ null hypothesis could not be rejected. Hence $\mathrm{H}_{3}$ is not supported.

Table 3: Results of mediation analysis

\begin{tabular}{l|c|c|c|c}
\hline \multicolumn{5}{c}{ Overall Model results } \\
\hline & $\begin{array}{c}\text { Unstand- } \\
\text { ardized Coef. }\end{array}$ & $\begin{array}{c}\text { Standard } \\
\text { Error }\end{array}$ & t-stat & P \\
\hline Knowledge & 1.0208 & 0.09 & 11.06 & 0.00 \\
\hline Constant & 0.7191 & 0.03 & 24.53 & 0.00 \\
\hline Exposure & 0.5869 & 0.10 & 5.62 & 0.00 \\
\hline Familiarity & 0.9290 & 0.048 & 19.53 & 0.00 \\
\hline Constant & 0.1861 & 0.05 & 4.13 & 0.00 \\
\hline Knowledge & 1.7109 & 0.14 & 11.85 & 0.00 \\
\hline Exposure & 0.0470 & 0.05 & 0.92 & 0.36 \\
\hline Sighted & 0.0775 & 0.03 & 2.07 & 0.04 \\
\hline Constant & -0.0512 & 0.04 & -1.41 & 0.16 \\
\hline Knowledge & 0.3208 & 0.04 & 7.23 & 0.00 \\
\hline Familiarity & Exposure & \multicolumn{4}{|l}{} \\
\hline Blind &
\end{tabular}

Mediation results

\begin{tabular}{|c|c|c|c|c|c|}
\hline \multicolumn{6}{|c|}{ Direct effect of Exposure $(X)$ on Sighted assessment $(Y)$} \\
\hline $\begin{array}{c}\text { Effect } \\
\text { Size }\end{array}$ & SE & t-stat & $\begin{array}{l}\mathbf{P} \\
*\end{array}$ & $\underset{* *}{\mathbf{L L C I}}$ & $\underset{* * *}{\text { ULCI }}$ \\
\hline-0.0512 & 0.036 & -1.41 & 0.16 & -0.1225 & 0.0202 \\
\hline \multicolumn{6}{|c|}{ Indirect effects of Exposure $(X)$ on Sighted assessment $(Y)$} \\
\hline & & $\begin{array}{c}\text { Effect } \\
\text { Size }\end{array}$ & SE & LLCI & ULCI \\
\hline \multicolumn{2}{|c|}{ Total } & 0.0999 & 0.0285 & 0.0439 & 0.1544 \\
\hline \multicolumn{2}{|c|}{$\mathrm{BE} \rightarrow \mathrm{BK} \rightarrow$ Sighted } & 0.0338 & 0.0254 & -0.0340 & 0.1055 \\
\hline \multicolumn{2}{|c|}{$\mathrm{BE} \rightarrow \mathrm{BK} \rightarrow \mathrm{BF} \rightarrow$ Sighted } & 0.0517 & 0.0232 & 0.0071 & 0.0979 \\
\hline \multicolumn{2}{|c|}{$\mathrm{BE} \rightarrow \mathrm{BF} \rightarrow$ Sighted } & 0.0144 & 0.0080 & 0.0025 & 0.0343 \\
\hline
\end{tabular}
Limited of Confidence Interval

\section{Conclusions and recommendations}

This study aimed to assess the mediating influence of certain brand awareness dimensions on sighted quality assessments when made in the presence of a particular wine brand. To this end a two-stage blind versus sighted taste experiment was conducted with 140 subjects. The experiment was designed such that each respondent was exposed to one sighted cue only: the wine brand. A mediation model was then computed to assess the extent to which $\mathrm{BK}, \mathrm{BE}$ and $\mathrm{BF}$ collude in the sighted assessment of wine brands when controlling for blind-based scores.

Building on the literature of Priilaid et al. (2013) this study suggests that BF does indeed mediate the sighted assessment of a wine when in the presence of a brand. This effect is shown to be particularly interesting given that the study sample consists of primarily younger respondents. Notably, fifty percent of the sample ranged between the ages of 18 and 22. Given this particular age bias, these results point to the importance of $\mathrm{BE}$ as a driver of $\mathrm{BK}, \mathrm{BF}$ and ultimately the sighted assessment of wine itself. This suggests that 
marketing activities aimed at promoting $\mathrm{BE}$ are indeed worthwhile. It should be noted moreover that BF mediates the relationship between BE and sighted assessments. This suggests that that merely exposing young novices to a brand (61\% of the sample classified themselves as novices in terms of their expertise in wine) is not sufficient to yield consistently high sighted assessment scores. From a marketing perspective, this observation supports the notion that conventional mass-media-driven marketing, though critically important to create $\mathrm{BE}$, is in itself not enough. Rather, our results suggest that the marketing effort has to engage customers from this group in a manner that fuels sufficient degrees of BF required ultimately to drive sighted assessment scores. The import of both these results is further confirmed by the absence of a statistical significant association between BE and sighted assessment. Exposure does not independently drive hedonic utility. Finally, the absence of a mediation effect of $\mathrm{BK}$ in the relationship between $\mathrm{BE}$ and sighted assessment remains equally important; suggesting that only imparting knowledge (information) to consumers, but not creating familiarity per $s e ́$ by engaging them in a meaningful multi-directional manner, may prove a futile exercise. Clearly the extent of the efficacy of BK and brand information cannot be fully addressed from the limited perspective of our analysis, and further corroborative research is required. However, in terms of young novice consumers, these findings do raise interesting questions about how wine marketers might better interact with these customers.

\section{Limitations and future research}

The potential limitations of this study pertain to the somewhat taxing nature of the chosen experiment (Dunphy \& Lockshin, 1998), wherein respondents were required to taste and evaluate eight wines in the first round and seven in the second. While this number pales in to insignificance when compared to the volume attested by wine professionals, to novices, this might have presented as a somewhat large wine sampling and we speculate that its repetitive character might potentially have caused some palate fatigue during the experiment; an effect which may or may not have led some respondents to inflate or reduce the variation between their blind and sighted assessments. Such variation may be incorrectly attributed to the effects of BF.

Further limitations may exist in the challenges associated with controlling the prevailing experimental conditions. Despite the researchers taking every precaution to standardise the experiential conditions, inevitably variations emerged across the range of responses to tasting the wine, in the use of palate cleansers, in the time taken to consider the rating and in the level of circumspection applied. In addition to this, the group setting of the experiment meant that respondents were susceptible to influence by other respondents through group discussion and interaction, and the spontaneous commentary by individuals.

Future studies could also replicate this study using wine brands with greater variation in price. Many empirical pieces have found that price is used as a general indicator of quality (Brucks et al., 2000; Rao \& Monroe, 1989; Zeithaml, 1988). Therefore, a greater price variation implies greater variation in perceived quality. The current study made use of brands that were similar in price (R50-R80) and therefore, perceived quality. Potentially future research could conduct the study using wines of a greater wine range in order to determine whether BF effects are stronger for high and low-end brands.

In addition to this, future research should investigate the relationship between price, $\mathrm{BF}$ and blind versus sighted taste assessments. Based on observations during data collection, researchers noted that when respondents were familiar with the brand they were also familiar with the price. Such brandprice conflation is likely to have influenced the respondents' sighted taste assessments, and future research could well explore the relationship between $\mathrm{BF}$ and price by simultaneously exposing respondents to both brand and price information.

\section{References}

Aaker, D.A. 1996. 'Measuring brand equity across products and markets', California Management Review, 38(3):102-122.

Allison, R. \& Uhl, K. 1964. 'Influence of beer brand identification on taste perception', Journal of Marketing Research, 1(3): 36-39.

Ariely, D. \& Norton, M. 2009. 'Conceptual consumption', Annual Review of Psychology, 60(January): 475-499.

Baron, R.M. \& Kenny, D.A. 1986. 'The moderator-mediator variable distinction in social psychological research: Conceptual, strategic, and statistical considerations', Journal of Personality and Social Psychology, 51(6):1173.

Brucks, M. Zeithaml, V.A. \& Naylor, G. 2000. 'Price and brand name as indicators of quality dimensions for consumer durables', Journal of the Academy of Marketing Science, 28(3): 359-374.

Bruner, G.C. 2013. Marketing Scales Handbook: Multi-Item Measures for Consumer Insight Research. Volume 7. Fortworth, Texas: GCBII Productions.

Chocarro, R., Cortinas, M. \& Elorz, M. 2009. 'The impact of product category knowledge on consumer use of extrinsic cues - A study involving agrifood products', Food Quality and Preference, 20(3): 176-186.

Dahlén, M. \& Lange, F. 2004. 'To challenge or not challenge: adbrand incongruency and brand familiarity', Journal of Marketing Theory and Practice, 12(3):20-35.

Delgado-Ballester, E. Navarro, A. \& Sicilia, M. 2012. 'Revitalising brands through communication messages: The role of brand familiarity', European Journal of Marketing, 46(1/2): 31-51.

Dunphy, R. \& Lockshin, L. 1998. 'A contemporary perspective of the Australian wine show system as a marketing tool', Journal of Wine Research, 9(2): 107-129.

Durant, L.E. Carey, M.P. Schroder, K.E.E. 2002. 'Effects of anonymity, gender, and erotophilia on the quality of data obtained from self-reports of socially sensitive behaviors', Journal of Behaviour and Medicine, 25(5): 438-467. 
Erdem, T. \& Swait, J. 1998. 'Brand equity as a signalling phenomenon', Journal of Consumer Psychology, 7: 131-157.

Fournier, S. 1998. 'Consumers and their brands: Developing relationship theory in consumer research', Journal of Consumer Research, 24(4): 343-353.

Hayes, A.F. \& Preacher, K.J. 2010. 'Quantifying and testing indirect effects in simple mediation models when the constituent paths are nonlinear', Multivariate Behavioral Research, 45(4): 627-660.

Holbrook. M.B. \& Hirschman, E.C. 1982. 'The experiential aspects of consumption: consumer fantasies, feelings, and fun', Journal of Consumer Research, 9(2): 132-140.

Hirschman, E.C. \& Holbrook. M.B. 1982. 'Hedonic consumption: Emerging concepts, methods and propositions' Journal of Marketing, 46(3): 92-101.

Kahneman, D. 2012. Thinking, fast and slow. London: Penguin Books.

Kamakura, W.A. \& Russell, G.J. 1991. Measuring consumer perceptions of brand quality with scanner data: Implications for brand equity, $3^{\text {rd }}$ Edition. Upper Saddle River, NJ: Prentice Hall.

Keller, K.L. 2003. Strategic brand management: building, measuring and managing customer-based brand equity, Upper Saddle River, NJ: Pearson Education Inc.

Keller, K.L. 1993. 'Conceptualising, measuring and managing customer-based brand equity’, Journal of Marketing, 57(1): 1-22.

Kerr, W.C., Greenfield, T.K., Tujague, J. \& Brown, E. 2005. 'A drink is a drink? Variation in the amount of alcohol contained in beer, wine and spirits drinks in a US methodological sample', Alcoholism: Clinical and Experimental Research, 29(11): 20152021.

Kotler, G.M. \& Armstrong, G.M. 2010. Principles of marketing. $9^{\text {th }}$ Edition. Englewood Cliffs, NJ: Prentice Hall.

Labroo, A.A. \& Lee, A.Y. 2006. 'Between two brands: a goal fluency account of brand evaluation', Journal of Marketing Research, 43(3): 374-85.

Lange, F. \& Dahlén, M. 2003. 'Let's be strange: Brand familiarity and ad-brand incongruency', Journal of Product and Brand Management, 12(6/7): 449-461.

Lassar, W. Mittal, B. \& Sharma, A. 1995. 'Measuring customerbased brand equity', Journal of Consumer Marketing, 12(4): 11-19. Lee, A. \& Labroo, A. 2004. 'The effect of conceptual and perceptual fluency on brand evaluation', Journal of Marketing Research. 41(2): 151-165.

Lockshin, L., Jarvis, W., d'Hauteville, F. \& Perrouty, J. 2006. 'Using simulations from discrete choice experiments to measure consumer sensitivity to brand, region, price, and awards in wine choice', Food Quality and Preference, 17(3-4): 166-178.

Madhavaram, S. Badrinarayanan, V. \& McDonald, R.E. 2005. 'Integrated marketing communication (IMC) and brand identity as critical components of brand equity strategy', Journal of Advertising, 34(4): 69-80.
Malhotra, N.K. 2010. Marketing research: An applied orientation. $6^{\text {th }}$ Edition. Upper Saddle River, NJ: Pearson Education Inc.

McClure, S., Li, J., Tomlin, D., Cypert, K., Montague, L. \& Montague, P. 2004. 'Neural correlates of behavioural preferences for culturally familiar drinks', Neuron, 44(2): 379-387.

Novemsky, N. Dhar, R. Schwarz, N. \& Simonson, I. 2007. 'Preference fluency on choice', Journal of Marketing Research, 44(3): 347-56.

Oliver, R. L. \& Bearden, W.O.1985, 'Crossover effects in the theory of reasoned action: a moderating influence attempt', Journal of Consumer Research, 12(3): 324-340.

Paasovaara, R., Luomala, H.T., Pohjanheimo,T. \& Sandell, M. 2012. 'Understanding consumers' brand-induced food taste perception: A comparison of 'brand familiarity' -and 'consumer value - brand symbolism (in)congruity'- accounts', Journal of Consumer Behaviour, 11: 11-20.

Plassmann, H., Ramsøy, T.Z. \& Milosavljevic, M. 2012. 'Branding the brain: A critical review and outlook', Journal of Consumer Psychology, 22(1): 18-36.

Plassmann, H., O'Doherty, J., Shiv, B. \& Ranjul, A. 2008. 'Marketing actions can modulate neural representations of experienced pleasantness', Proceedings of the National Academy of Sciences, 105(3): 1050-1054.

Preacher, K.J. \& Hayes, A.F. 2008. 'Asymptotic and resampling strategies for assessing and comparing indirect effects in multiple mediator models', Behavior Research Methods, 40(3): 879-891.

Priilaid, D. \& van Rensburg, P. 2010. 'Symbolic and functional brand effects in the hedonic assessment of South African wines', South African Journal of Business Management, 41(3): 47-69.

Priilaid, D. \& van Rensburg, P. 2016. 'How price-effects accrue with product experience and expertise', Food Quality and Preference, 48: 166-173.

Priilaid, D. 2007. 'The placebo of place: Terroir effects in the blind and sighted quality assessments of South African varietal wines', Journal of Wine Research, 18(2): 87-105.

Priilaid, D. Barendse, J. Kato-Kalule, C. \& Mubangizi, A. 2013. 'Flies in amber: Capturing brand equity effects in South African rosé wines', South African Journal of Business Management, 4(3): 1523.

Priilaid, D., Feinberg, J., Carter, O. \& Ross, G. 2009. 'Follow the leader: How expert ratings mediate consumer assessments of hedonic quality', South African Journal of Business Management, 40(4): $51-58$

Rao, A.R. \& Monroe, K.B. 1989. 'The effect of price, brand name, and store name on buyers' perceptions of product quality: An integrative review', Journal of Marketing Research, 26(3): 351-357.

Robinson, T.N., Borzekowski, D.G., Matheson, D.M. \& Kraemer, H.C. 2007. 'Effects of fast food branding on young children's taste preferences', Archives of Pediatrics and Adolescent Medicine, 161: 792-797. 
Seghieri, C., Casini, L. \& Torrisi, F. 2007. 'The wine consumers' behaviour in selected stores of Italian major retailing chains', International Journal of Wine Business Research, 19(2): 139-151.

Sherman, S. \& Tuten, T. 2011. 'Message on a bottle: the wine label's influence', International Journal of Wine Business Research, 23(3): 221-234.

Shiv, B., Carmon, Z. \& Ariely, D. 2005. 'Placebo effects of marketing actions: Consumers may get what they pay for', Journal of Marketing Research, 42(4): 383-393.

Siegrist, M. \& Cousin, M. 2009. 'Expectations influence sensory experience in a wine tasting', Appetite, 52: 762-765.

Solnais, C. Andreu-Perez, J. Sanchez-Fernandez, J. \& AndreuAbela, J. 2012. 'The contribution of neuroscience to consumer research: A conceptual framework and empirical review', Journal of economic psychology, 36(1): 68-81.

Steenkamp, J.B.E., Batra, M.J. \& Alden, D.L. 2003, 'How perceived brand globalness creates brand value', Journal of International Business Studies, 34(1): 53-65.

Stewart-Williams, S. \& Podd, J. 2004. 'The placebo effect: Dissolving the expectancy versus conditioning debate', Psychological Bulletin, 130(2): 324-340.

Tam, J.L.M. 2008. 'Brand familiarity: Its effects on satisfaction evaluations', Journal of Services Marketing, 22(1): 3-12.

Thrane, C. 2004. 'In defence of the price hedonic model in wine research', Journal of Wine Research, 15(2): 123-134.

Waber, R., Shiv, B., Carmon, Z. \& Ariely, D. 2008. 'Commercial features of placebo and therapeutic efficiency', Journal of American Medical Association, 299(9): 1016-1017.

Yuan, J.J. \& Jang, S.S. 2008. 'The effects of quality and satisfaction on awareness and behavioral intentions: Exploring the role of a wine festival', Journal of Travel Research, 46(3): 279-288.

Zeithaml, V.A. 1988. 'Consumer perceptions of price, quality, and value: A means-end model and synthesis of evidence', The Journal of Marketing, 52(3): 2-22.

Zhou, L, Yang, Z \& Hui, M.K. 2010. 'Non-local or local brands? A multi-level investigation in to confidence in brand origin identification and its strategic implications', Journal of Academy of Marketing Science, 38(2): 202-218. 


\section{Appendix}

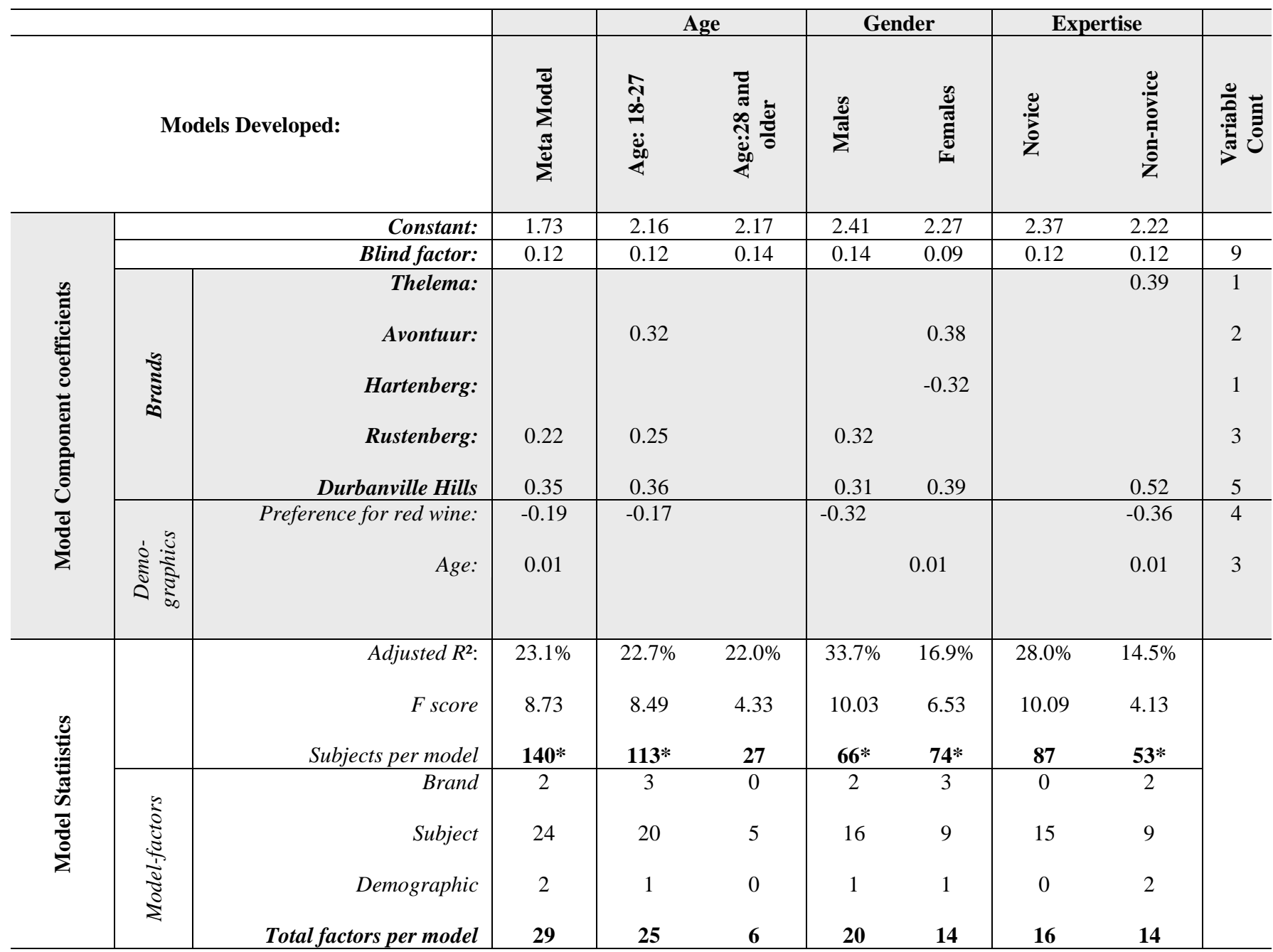

Summation table of brand effects identified across the demographic models computed prior to the mediation analysis. (*: Note: subject-data extracted for this paper's analysis sum to 446 respondents $(140 *+113 *+66 *+74 *+53 *))$. 